A R T I G O

\title{
NARCOCULTURA VISUAL E FEMINISMO LIBERAL: UM ESTUDO DE CASO
}

Visual narcoculture and liberal feminism: a case study

Narcocultura visual y feminismo liberal: un estudio de caso

MARINA SOLER JORGE ${ }^{\text {I** }}$

DOl: https://doi.org/10.1590/S2178-149420210108

'Universidade Federal de São Paulo - São Paulo (SP), Brasil.

*Professora associada do Departamento de História da Arte da Universidade Federal de São Paulo e do Programa de PósGraduação em História da Arte (e-mail: marina.soler@unifesp.br).

(D) http://orcid.org/0000-0002-3352-7509

Artigo recebido em 31 agosto de 2020 e aprovado para publicação em 11 novembro de 2020. 


\title{
RESUMo
}

Com base na metodologia dos estudos culturais, este artigo tem um duplo objetivo: em primeiro lugar, abordaremos as narconarrativas latino-americanas na cultura visual contemporânea, procurando demonstrar que elas ocupam um lugar importante no cenário do audiovisual globalizado. Em seguida analisaremos de que modo algumas dessas produções se utilizam de temáticas aparentemente feministas, inserindo personagens femininos fortes em ambientes muito masculinos e patriarcais, bem como os limites dessas representações, dados pelo fato de que estas não ultrapassam o espectro do feminismo liberal. Argumentaremos, nesse sentido, que temáticas feministas têm sido utilizadas de modo pouco crítico, funcionando para reforçar alguns valores capitalistas-patriarcais.

PALAVRAS-CHAVE: Séries de TV; Feminismo; Narconarrativas; Estudos Culturais.

\begin{abstract}
Based on cultural studies methodology, this article had a double aim: firstly, it addressed Latin American narconarratives in contemporary visual culture, showing that they occupy an important place in the globalized audiovisual scene. Then, we analyzed how some of these productions use apparently feminist themes, representing strong female characters in very masculine and patriarchal environments, as well as the limits of these representations, given the fact that they do not cross the spectrum of liberal feminism. We will argue, in this sense, that feminist themes have been used in an non-critical way, serving to reinforce some capitalistpatriarchal values.
\end{abstract}

KEYWORDS: TV Shows; Feminism; Narconarratives; Cultural Studies.

\section{RESUMEN}

Partiendo de la metodología de los estudios culturales, este artículo tiene un doble objetivo: en primer lugar, abordaremos las narrativas latinoamericanas en la cultura visual contemporánea, tratando de demostrar cómo ocupan un lugar importante en el panorama audiovisual globalizado. Luego analizaremos cómo algunas de estas producciones utilizan temas aparentemente feministas, insertando fuertes personajes femeninos en ambientes muy masculinos y patriarcales, así como los límites de estas representaciones, dado que estas no atraviesan el espectro del feminismo liberal. Argumentaremos, en este sentido, que los temas feministas han sido utilizados de manera poco crítica, sirviendo para reforzar algunos valores capitalistas-patriarcales.

PAlAbRAS ClaVE: Series de Televisión; Feminismo; Narconarrativas; Estudios Culturales. 


\section{CULTURA VISUAL E NARCONARRATIVAS}

$\mathrm{O}$ narcotráfico define, em grande medida, a representação da América Latina na cultura visual contemporânea. Ainda que os Estados Unidos sejam os maiores consumidores de drogas na América, o audiovisual tende a representar o narcotráfico como um problema sobretudo da Colômbia, Bolívia, México e Brasil. A cultura hegemônica relaciona-o ao subdesenvolvimento, à corrupção política e policial e à pobreza, mas frequentemente ignora o contexto mais geral do modo de produção capitalista, sobretudo no que se refere à associação entre a guerra às drogas (war on drugs) lançada pelos Estados Unidos nos anos 70, à ascensão do neoliberalismo e à consolidação do narcotráfico na América Latina (Cabañas, 2014). É possível dizer que parte importante da cultura visual moderna e contemporânea constrói sobre a América Latina uma representação politicamente interessada, explorando sua criminalidade e seus problemas sociais como se essas mazelas brotassem de nosso fértil solo tropical.

Crime, marginalidade e violência não são assuntos novos no cinema e na televisão, e em muitas ocasiões suas representações tiveram forte apelo estético, como no gênero noir, por exemplo, que estabeleceu uma visualidade elegante, caracterizada pelo contraste entre luz e sombra. A cultura visual contemporânea inova ao aplicar o apelo estético, construído com base em direção de arte bem cuidada, bela fotografia, montagem excitante e trilha sonora pop à criminalidade latino-americana, considerada típica de favelados, "desqualificados", paisás, cocaleros e homens pobres e pouco escolarizados imersos no subdesenvolvimento. Novamente, não se questionam de modo mais profundo as condições sociais que permitem o surgimento do narcotráfico — ainda que a segunda temporada de Narcos México tenha tematizado o papel do Departamento de Estado dos Estados Unidos, o deep state, na manutenção do comércio de drogas - , mas este passa a ser embalado em uma forma estética agradável e empolgante, que perpassa a cultura visual hegemônica.

Ao longo da última década temos visto um intrigante ressurgimento, por exemplo, de produtos culturais inspirados na vida de Pablo Escobar, como séries, telenovelas e livros, fenômeno analisado em alguns artigos acadêmicos (ver, por exemplo, Pobutsky, 2013 e Gradeja, 2017). Talvez inspiradas por filmes estadunidenses de máfia nos quais o gângster se apresenta como vaidoso e preocupado com a aparência (Bruzzi, 1997), as narconarrativas latino-americanas passaram a apresentar o traficante como um consumidor de bens de luxo, aburguesando-o, mas novamente ignorando o contexto mais geral do modo de produção capitalista que cria o desejo de bens destinados à distinção e à exclusividade em sociedades marcadas pela desigualdade. 
Quando as narconarrativas se descolam de seu local de origem, tornando-se parte do que Renato Ortiz denominou de cultura internacional-popular (1994), é importante entender seu potencial de construção de visões de mundo e suas políticas de representação. A moda narco espalha-se e homogeneíza-se pelo planeta, fazendo parte da cultura de massas simbolicamente legítima, consumida por pessoas que não compartilham de sua origem social. Na América Latina, narcocorridos e pancadões, por exemplo, passam a ser ouvidos por jovens de classe média, e músicas que exaltam a criminalidade atingem o topo das paradas nos Estados Unidos e em diversos países da Europa. A narcocultura constitui-se precisamente em cultura visual — uma narcocultura visual, poderíamos dizer — na medida em que é uma das expressões culturais da sociedade contemporânea e que se manifesta sobretudo em visualidades, seja nos filmes, séries e videoclipes, seja nas vestimentas.

Omar Rincón é um dos autores que estuda a narcocultura na contemporaneidade e o paradoxo decorrente do fato de que, enquanto o tráfico é combatido com armas, "sua estética é celebrada" (Rincón, 2013: 209). Colombiano, ele argumenta que todos os latino-americanos "têm um pouco de tráfico" dentro de si, pois vivem em culturas nas quais "toda lei pode ser comprada, vale tudo para se promover socialmente, a felicidade é agora, o sucesso deve ser demonstrado pelo consumo, a lei é boa se funciona para mim, o consumo é o motivador do poder" (Rincón, 2013: 194). Analisando a mudança na forma de representação do narcotráfico, ele dirá: "No início, era um assunto de pobres feios, com o tempo, de feios e belas, e finalmente, de ricos e famosos" (Rincón, 2013: 194).

No Brasil, Maurício de Bragança é um dos pesquisadores que têm se dedicado ao tema da narcocultura no audiovisual. Para ele, as mídias são lugares de disputas políticas e estratégias de representação, nas quais as imagens do mundo do crime surgem como elemento relevante na contemporaneidade. Bragança chama a atenção para os efeitos práticos que essa representação enseja, no sentido de fortalecer uma cultura a despeito de seus prejuízos para a sociedade:

A inscrição da produção, da circulação, do comércio e do consumo de drogas também está intimamente ligada à permanência de um narcoimaginário que ganha relevo se observado sob 0 aspecto de uma produção narcocultural. Tal aspecto tem sido absolutamente negligenciado pelos poderes públicos, que se recusam a perceber que esses discursos constroem redes de sociabilidade e forjam práticas sociais que garantem laços identitários importantes. (Bragança, 2012: 107).

Em outro artigo, o mesmo autor discorre sobre a relevância de se entenderem as manifestações culturais relacionadas ao narcotráfico, na medida em que elas "encaminham im- 
portantes discussões capazes de desvelar um rico imaginário em torno das práticas simbólicas latino-americanas atravessadas pela experiência de uma modernidade periférica que tensiona os paradigmas da modernidade ocidental" (Bragança, 2015: 153).

Segundo W. J. T. Mitchell (2006: 4), o termo "cultural visual" designa o objeto de estudos dos chamados estudos visuais, que compreende um "campo expandido de pesquisas cujas fronteiras são imprecisas", englobando

não apenas a história da arte e a estética, mas imagens técnicas e científicas, filmes, televisão e meios digitais, como também reflexões filosóficas sobre a epistemologia da visão, estudos semióticos de imagem e signos visuais, a investigação psicanalítica do impulso visual, estudos fenomenológicos, fisiológicos e cognitivos do processo visual, estudos sociológicos sobre a exibição e o espectador, antropologia visual, ótica e visão animal, dentre tantas outras. (Mitchell, 2006: 4).

Segundo Douglas Crimp, os estudos visuais, por sua vez, são "uma área mais estreita dos estudos culturais" (Crimp, 1999: 80). Este último, campo interdisciplinar que tem sua origem na Universidade de Birmingham, Inglaterra, nos anos 1960, que entende a cultura como a dimensão que conecta as experiências sociais mais relevantes na contemporaneidade. Stuart Hall, um dos expoentes dos estudos culturais, considera que vivemos em uma era marcada pela centralidade da cultura: "a enorme expansão de tudo o que está associado a ela, na segunda metade do século XX, e o seu papel constitutivo, hoje, em todos os aspectos da vida social" (Hall, 1997: 1).

Medeiros e Castro, por outro lado, entendem a preocupação com a cultura visual como originária das intuições de historiadores da arte, que passam a estudar seus objetos de uma perspectiva não artística, abertos "às dimensões cultural e historicamente variáveis das formas de olhar e das experiências visuais" (Medeiros e Castro, 2017: 1). Entre esses historiadores estariam Michael Baxandall e sua obra sobre a pintura renascentista, Aby Warburg e seu interesse por uma história cultural da imagem e as incursões de Erwin Panofsky nos estudos de cinema. Segundo as autoras, são culminantes nesse processo — com base no qual a história da arte expande as possibilidades de compreensão do objeto estético — os programas de John Berger para a BBC inglesa, Ways of Seeing, nos quais gêneros representativos usualmente considerados distantes, como a pintura e a propaganda, são aproximados para desvendar dimensões culturais do olhar.

Autores que estudam o campo, entre os quais o próprio Mitchell, chamam a atenção para o fato de que os estudos visuais não emitem juízos estéticos, interessando-se igualmente pela arte erudita e pela cultura de massas como aspectos igualmente reveladores de uma determinada cultura visual. Essa desconsideração pela estética foi alvo de críticas, sobretudo 
de historiadores da arte mais ligados a seu campo disciplinar de origem. Douglas Crimp, por exemplo, faz um apanhado dos argumentos dos intelectuais que se colocam contra os estudos visuais, entre os quais aqueles de Martin Jay, "que reclama de um 'nivelamento pseudopopulista de todos os valores culturais'" (Jay apud Crimp, 1999: 80). Renato Ortiz explica que, até a chegada das perspectivas interdisciplinares dos estudos culturais, o âmbito da cultura estava efetivamente compartimentado em níveis de qualidade e de fruição, de modo que os estudos literários e a estética não dialogavam com a antropologia - que se interessava sobretudo pela cultura popular - , enquanto a sociologia tendia a considerar a cultura de massas como assunto de menor importância (Ortiz, 2004: 124). Com os estudos visuais, os aspectos culturais relacionados à visualidade passam a ter maior importância, de modo que a antropologia é chamada a colaborar na compreensão de produtos culturais e artísticos, sejam eles eruditos, populares ou massificados.

A globalização é elemento importante para se pensar a cultura visual, tendo em vista que a diminuição das distâncias espaço-temporais engendrada pelos meios de comunicação e pela circulação de capital produz, nas palavras de Stuart Hall, uma "tendência à homogeneização cultural" (Hall, 1997: 3). Hall destaca, no entanto, que as consequências desse processo "não são nem tão uniformes nem tão fáceis de ser previstas da forma como sugerem os 'homogeneizadores' mais extremados" (Hall, 1997: 3).

Globalização e homogeneização cultural são fenômenos importantes para a compreensão do objeto do presente artigo. Desde os primeiros anos do século XXI, temos acompanhado a proliferação de produtos audiovisuais relacionados à representação do narcotráfico em canais pagos de televisão e plataformas de streaming. Pode-se dizer que estamos em um período de grande vitalidade de uma narcocultura visual. 0 que nos chama a atenção nesses produtos é que eles têm sido direcionados em grande medida a um público internacional e não apenas ao mercado local e seus gostos regionais. Assim, nos termos dos estudos culturais, estamos observando esse processo de globalização e homogeneização da figura do narcotraficante, que agora circula nas plataformas de streaming e se afasta da latinidade folhetinesca das telenovelas. Esse processo, evidentemente, não significa um apagamento das identidades culturais latino-americanas — ainda estão lá o idioma castelhano nas vertentes colombianas e mexicanas, com seus maravilhosos sotaques e palavrões, e a tendência de alguns produtos a beber da fonte do melodrama televisivo - , mas um entrelaçamento entre essas identidades e a estética globalizada das séries de televisão.

Por fim, é importante mencionar a importância da dimensão política para o estudo da cultura visual: "os estudos culturais devem ser vistos tanto do ponto de vista político, na 
tentativa de constituição de um projeto político, quanto do ponto de vista teórico, isto é, com a intenção de construir um novo campo de estudos" (Escosteguy, 1998: 88).

Douglas Crimp cita a crítica de Rosalind Krauss a esse aspecto:

Os estudantes dos cursos de pós-graduação em história da arte não estão aprendendo as habilidades necessárias para interpretar as obras de arte. Em vez disso, estão fazendo estudos visuais - um monte de cenários paranoicos sobre o que acontece sob o patriarcado ou sob o imperialismo. (Krauss apud Crimp, 1999: 80).

Assumindo a metodologia eminentemente política e interdisciplinar dos estudos culturais, é justamente isso o que pretendemos fazer na continuação deste artigo: uma análise, que os críticos talvez considerem paranoica, de uma das manifestações mais disfarçadas do patriarcado no interior da narcocultura visual. Utilizaremos aqui o conceito de patriarcado tal como exposto na obra de Gerda Lerner $A$ criação do patriarcado. Temos consciência de que a opressão das mulheres não se manifesta igualmente em todas as culturas, mas que, em nossa sociedade, faz parte de um processo histórico e dinâmico que se desenrolou ao longo de milhares de anos, pautado pelas configurações do núcleo familiar:

Patriarcado, em sua definição mais ampla, significa a manifestação e institucionalização da dominância masculina sobre as mulheres e crianças na família e a extensão da dominância masculina sobre as mulheres na sociedade em geral. A definição sugere que homens têm 0 poder em todas as instituições importantes da sociedade e que mulheres são privadas de acesso a esse poder. Mas não significa que as mulheres sejam totalmente impotentes ou privadas de direitos, influência e recursos. (Lerner, 2019: 290).

\section{MULHERES NA NARCOCULTURA}

o mesmo tempo em que constroem visões de mundo sobre a América Latina, a narco-
cultura visual cria representações sobre a mulher latino-americana, bem como representações femininas em geral. Estas são quase sempre conservadoras e tradicionais, no sentido de que apresentam as mulheres passivas, frequentemente em suas casas e, no interior delas, em espaços específicos, como na piscina cuidando de seus filhos e na cozinha cozinhando com outras mulheres da família e amigas. Mulheres são raramente vistas, nessas séries, nos mesmos espaços de trabalho que os homens, sobretudo quando se fala de negócios - cujos resultados, no caso do narcotráfico, impactam diretamente a vida das famílias. 0 narcotráfico e o combate a ele não são usualmente representados como tarefas femininas, de modo que a criminalidade é também generificada. Como nos explica Grossi, essa representação das mulheres como passivas e dos homens como agressivos, propensos à criminalidade, perpassa 
nossa sociedade; e não apenas a cultura visual, uma vez que "já na constituição da identidade de gênero na infância, observamos como o masculino se constitui pela hiperatividade dos meninos, que se confunde seguidamente com agressividade" (Grossi, 2004: 6).

As mulheres nas narconarrativas tendem a preencher os papéis de esposas e amantes, em grande medida definidos como propriedades do homem, parte de seus bens de consumo. Dessa maneira, a narcocultura contemporânea, ao dar visibilidade a esse tipo de representação feminina, colabora de fato para manter certa invisibilidade sobre a mulher, seja porque a relega a tarefas narrativas menos importantes, seja porque, ao invés de discutir a estrutura social que cria homens violentos e mulheres submissas, a naturaliza. A narcocultura visual não é, no entanto, um campo unidimensional: mesmo em cada produto é possível encontrar conflitos entre as representações. Na terceira temporada de Narcos, por exemplo (não o Narcos México, mas o Narcos colombiano), a personagem de Maria, mulher-troféu de um poderoso traficante, que nunca havia tido qualquer protagonismo até então, desempenha uma ação crucial e inesperada para acabar com o cartel de seu marido e garantir sua sobrevivência e a de seu filho. A cultura visual, como expressão das variadas dimensões políticas e ideológicas que se embatem na sociedade, é um campo no qual certas representações hegemônicas - ou dominantes para falarmos como Raymond Williams (1979) —, devedoras tanto das convenções de gênero quanto das convenções sociais, tendem a ter prevalência, sem no entanto esmagar representações alternativas que também circulam na sociedade.

É possível argumentar que a representação das mulheres na narcocultura visual corresponde à realidade da situação dessas mulheres no narcotráfico, no sentido de que elas são efetivamente relegadas aos papéis de objeto sexual e esposa, que usualmente não tomam parte dos negócios e que são, sobretudo, mulheres-troféus dos narcotraficantes. Sobre esse argumento faremos duas ponderações: em primeiro lugar, a chamada realidade não existe sem uma representação cultural e social que the dê legitimidade social, ou seja, a dominação masculina encontra na cultura uma fonte de justificação, e até mesmo naturalização, da exploração feminina. A opressão das mulheres, em outras palavras, é reafirmada a todo momento na produção cultural de uma determinada sociedade, invisibilizando a agência feminina e naturalizando práticas como a dupla jornada de trabalho, o cuidado com o outro e a estetização excessiva. Por outro lado, a violência masculina, como já mencionamos, também é naturalizada, de modo que se espera de um homem que ele seja o elemento ativo da relação (Grossi, 2004: 9).

Isso quer dizer que, ao mesmo tempo em que o patriarcado cria culturas de passividade e agressividade generificadas, suas representações visuais passam a legitimá-lo e a normalizá-lo, tendo portanto um efeito prático sobre a realidade. Em segundo lugar, a impressão de 
realidade advinda do cinema e do audiovisual é em grande medida decorrente da materialidade desse meio artístico e da forma pela qual ele tem sido comumente utilizado, ou seja, para contar histórias de uma forma naturalista, apropriando-se da ideia pictórica renascentista de janela para o mundo. Assim nos iludimos e obtemos grande prazer dessa ilusão de que estamos vendo o mundo se desenrolar diante de nós. No caso das narconarrativas latino-americanas contemporâneas, temos um relato interessante que nos ajuda a colocar em perspectiva a representação feminina nas séries: a viúva de Pablo Escobar, Victoria Henao (Tata), escreveu recentemente uma autobiografia que conta uma história completamente diferente daquela que vemos em Narcos (Henao, 2019). Ainda que esse relato também possa apresentar alto teor de ficcionalidade, o importante é que ele conflita diretamente com a representação feita dela em Narcos, ensejando uma contranarrativa poderosa. 0 relato da Tata "real" é completamente desprovido do glamour que cerca a personagem da série. Além disso, o impacto do narcotráfico na sua vida é assustador e, se filmado, produziria uma série mais interessante do que a sobre seu marido. Não se trata de uma mulher que teve grande participação nos negócios do marido; ela foi, acima de tudo, mãe e uma mulher bastante solitária. No entanto, o desempenho da função de mãe para a Tata "real" é muito mais complicado do que vemos na série, na medida em que a criminalidade e a violência pesam imensuravelmente no cuidado com o outro, e portanto nas mulheres de modo geral. Ao mesmo tempo, ela discute sua situação de esposa compulsória, tendo em vista que sabe que não pode abandonar o marido sob risco de ser assassinada pelo próprio. Por fim, temos o relato do estupro que ela sofreu de Escobar quando tinha 13 anos, resultando em uma gravidez e um debilitante aborto, e que ela só percebe ter sido um estupro muitas décadas depois, ao fazer psicoterapia.

Passaremos agora a analisar três séries que aparentemente procuram mudar a imagem tradicional das mulheres em narconarrativas: Queen of the South (2016), a primeira temporada de Narcos México (2018) e a última temporada de El chapo (2018). Trata-se de uma série e duas temporadas que procuram dar visibilidade a um outro tipo de mulher, que quer trabalhar e galgar posições de poder. As duas últimas são baseadas em eventos ocorridos no México entre 1980 e 2016 (a ascensão e queda de, respectivamente, Miguel Ángel Félix Gallardo e Joaquín Guzmán). Queen of the South é baseada no livro La reina del Sur, escrito pelo espanhol Arturo Pérez-Reverte, e é uma refilmagem da versão mexicana que tem Kate del Castillo no papel principal. Nossa metodologia para a análise da série é diretamente inspirada em uma importante pesquisadora dos estudos culturais, Angela McRobbie, e sua obra The afthermath of feminism: gender, culture and social change. McRobbie analisa alguns produtos culturais da contemporaneidade - como os livros de Bridget Jones, as propagandas de produtos femininos que exploram uma sexualidade agressiva e também programas de televisão baseados 
na transformação da aparência (as famosas séries de make-over) — e chega à conclusão de que, na contemporaneidade, elementos do feminismo foram incorporados à cultura visual. Fizeram-no, no entanto, sob a égide da falácia liberal da escolha e do empoderamento, com os objetivos de obscurecer os aspectos mais radicais do feminismo e enfraquecer suas demandas. Voltaremos a esse assunto mais à frente.

\section{AS SÉRIES E SUAS PERSONAGENS}

Entre muitos programas de TV, novelas e produtos de streaming que têm como assunto o tráfico de drogas na América Latina, escolhemos os três mencionados acima por dois motivos: sua estética internacional-popular e o fato de representarem a luta feminina por um lugar em ambientes masculinos. Como já mencionamos acima, no que diz respeito à forma, eles são desenraizados de seu local de origem e mostram-se como produtos internacionais que pretendem atingir um público heterogêneo. Embora tenham sido feitos com o público latino-americano em vista, apresentam diferenças em relação aos produtos locais, como as telenovelas mexicanas — incluindo a série mexicana La reina del Sur (2011, 2019-), que não teremos tempo de abordar neste artigo e que merece um trabalho específico - ou as produções lowbrow masculinas que exploram violência, situações sujas e corpos de mulheres nuas, como a série argentina sobre tráfico humano Estocolmo (2016). Isso fica claro quando observamos, por exemplo, o elenco e a cinematografia de Narcos, El chapo e Queen of the South. Em resumo, essas séries participam da ideia de "televisão de qualidade" propalada inicialmente entre os canais de televisão por assinatura. Assim, o que é importante para nós é refletir sobre como essas séries têm representado as mulheres latino-americanas - e as muIheres em geral — não apenas para o público local, mas para espectadores de diversas partes do mundo, bem como os limites dessa representação. Evitar uma estética mais regional e apelar para o mercado de massas internacionalizado ajuda a criar um aspecto de universalidade na representação, na medida em que a narrativa parece falar de um não lugar. Essa cultura visual internacional-popular, em suma, adquire uma aparência de neutralidade, empurrando as contranarrativas para nichos do mercado.

Como já mencionamos, filmes e séries que abordam gangues, máfias e traficantes de drogas geralmente se concentram em personagens masculinos, e as mulheres ao seu redor são construídas como parte de seu sistema de dominação. Isso é verdade para as temporadas 1, 2 e 3 de Narcos e para as temporadas 1 e 2 de El chapo, mas não para a primeira temporada de Narcos México, para a terceira temporada de El chapo e para toda a série Queen of the South. Nestas séries, vemos protagonistas femininas buscando ascender ao poder na política (El chapo) e no narcotráfico (Narcos México e Queen of the South). São personagens 
que não são mães ou esposas e não sonham em cuidar de um lar, mas, ao contrário, são muito "masculinas" em suas ambições e objetividade, ainda que muito "femininas" em sua aparência física. Nesse sentido, elas diferem da maioria de personagens mulheres que povoam as séries sobre narcotráfico e que habitam, de maneira naturalizada, os lares de traficantes de drogas ou agentes federais. A introdução dessas personagens nas narconarrativas parece corresponder a demandas de mercado, no intuito de atrair espectadoras que não se identificavam até então com a narcocultura e assim, conforme já mencionamos, atingir públicos mais heterogêneos.

Em El chapo temos Berta, senadora mexicana que se casa com o secretário de Segurança Pública, Conrado Sol - homossexual não assumido e um dos protagonistas da série — em um projeto de poder. Conrado é um dos personagens que faz de El chapo uma série interessante, pois por intermédio dele se apresentam as relações entre o tráfico de drogas e política, que são muito pouco exploradas na Narcos colombiana. El chapo é bastante explícita sobre o fato de que um poderoso narcotraficante — um dos mais ricos do mundo segundo a Forbes - não pode chegar a tais alturas sem a colaboração de políticos importantes e mesmo do gabinete presidencial. Conrado ganha poder usando de seu contato com Joaquín Guzmán, e não hesita em se livrar do traficante quando isso Ihe interessa. Trata-se, assim, de uma série em que o traficante de drogas tem como antagonista não um policial, mas um político tão ou mais imoral que ele.

Conrado está perto de alcançar seu objetivo, a presidência da República, e Berta quer trilhar o mesmo caminho político, mas, segundo a série, o México não está preparado nem para um homossexual nem para uma mulher independente. A solução é esconder suas vidas particulares por trás de um casamento de fachada, que Berta, mulher objetiva e racional, aceita sem nenhuma objeção. No entanto, o casamento é pequeno para a ambição de ambos, e Berta está sempre procurando algo que a coloque em vantagem como próxima candidata a presidente, no lugar de Conrado. Berta, portanto, é tão ambiciosa e competente quanto os homens da série e prova ser tão boa estrategista quanto Conrado. Para o espectador, observar o relacionamento entre Conrado e Berta, baseado em um delicado equilíbrio entre cooperação e sacanagem, é fonte de grande prazer narrativo, pois proporciona reviravoltas e suspense na trama.

Em Narcos México temos Isabella Bautista, uma personagem importante pelo fato de introduzir o traficante de drogas Miguel Angel Felix Gallardo, protagonista da temporada, no negócio da cocaína. Ela está com Miguel em vários momentos cruciais dos negócios, incluindo a reunião com os irmãos de Rodrigues Orejuela e Pablo Escobar, traficantes com os quais Miguel estabelece uma parceria. Do segundo episódio em diante, Isabella deixa claro que 
não está fazendo um favor a Miguel e que quer obter vantagens, o que não significa apenas dinheiro, mas, acima de tudo, poder na hierarquia do narcotráfico. Ela quer ter uma "praça" de distribuição de drogas, e todos os seus movimentos procuram levá-la para mais perto de seu objetivo.

Berta e Isabella são representadas como mulheres que têm desejos sexuais. Berta procura seu ex-marido toda vez que quer sexo, e Isabella tenta seduzir Miguel - que educadamente resiste - após cada negociação bem-sucedida. Nenhuma das duas quer um relacionamento amoroso e com envolvimento emocional, embora Berta pareça ter mais clareza sobre isso do que Isabella. Outro elemento que as aproxima é o fato de as duas mulheres sofrerem machismo em seus ambientes: Berta é frequentemente assediada por políticos que tecem comentários sobre sua aparência física, e em determinada ocasião um colega político chega a propor que ela seja sua mulher mantida. A série deixa claro que, como mulher, Berta não seria eleita presidente do México. Isabella também costuma ouvir comentários sobre sua aparência física, às vezes de maneira agressiva: a certa altura sua bunda é assunto de uma reunião, o que a deixa muito incomodada ("se eu fosse você, Miguel, a levaria para a Colômbia, os colombianos adoram uma bunda redonda"). Na Colômbia, de fato, ela é paquerada pelo traficante Chepe Santacruz. Mais tarde, quando ela e Miguel são sequestrados por Pablo Escobar, sugere-se que ela pode vir a ser vítima de violência sexual (o que acaba não ocorrendo). Ainda que representadas como mulheres atraentes pelos padrões masculinos da cultura contemporânea, nenhuma das duas quer usar da aparência para alcançar seus objetivos, e elas se ofendem quando são avaliadas pelos seus corpos e não pela inteligência.

Narcos México e El chapo são séries estreladas por homens nas quais personagens femininas ganham visibilidade para além de seus papéis passivos tradicionais em narconarrativas. Isabella e Berta querem entrar em um mundo definido por patriarcalismo e machismo. Isabella quer entrar no mundo masculino do narcotráfico, no qual as mulheres costumam ser mães, esposas, amantes, prostitutas e, acima de tudo, propriedades. Berta quer entrar no mundo masculino da política, no qual as mulheres são tratadas como intelectualmente inferiores e incapazes de governar.

Queen of the South lida com uma premissa diferente: nessa série, a personagem feminina, Teresa Mendoza, é a protagonista, como se pode antever pelo próprio título. Inicialmente ela não quer conquistar espaço em esferas tradicionalmente masculinas, ao contrário de Berta e Isabella; na verdade, ela está no início da série feliz e satisfeita com sua condição de namorada de um narcopiloto, desfrutando de uma vida de lazer e luxo e completamente apaixonada por ele. Ela é jogada no narcotráfico involuntariamente: seu namorado, Guero, é assassinado e ela tem de fugir para continuar viva. Nesse processo, ela descobre-se extrema- 
mente competente para os negócios ilícitos, pois é inteligente e hábil para sair de situações difíceis. Como heroína, é dotada de humanidade, é decente e justa em meio à violência do tráfico de drogas, o que nos permite torcer para que, ao final de cada episódio, ela continue viva. Ela coloca sua vida e negócios em risco, por exemplo, para salvar prostitutas da máfia russa. Mesmo com um bom coração, e também por causa dele, Teresa é capaz de galgar as posições mais altas no tráfico de drogas, e a série é a história de seu caminho para o sucesso. Como telespectadores, sabemos desde o início que ela alcançará o topo do narcotráfico, já que o fim nos é adiantado no começo da série, mas logo percebemos que não será fácil chegar lá, pois a trama está cheia de reviravoltas ao estilo rocambolesco. Nesse sentido, comparada a Narcos México e El chapo, Queen of the South está mais próxima das narrativas da telenovela, também pela aproximação com a série original mexicana: em quase todos os episódios, Teresa é colocada em uma situação cuja saída é aparentemente impossível, mas sempre consegue escapar. Assim, é interessante notar que Queen of the South mistura um gênero usualmente considerado muito feminino, a telenovela com origem no folhetim ${ }^{1}$, com uma narconarrativa, vista como mais masculina porque repleta de violência e ação. Em comparação a Isabella e Berta, Teresa não é objeto de assédio sexual, e a atriz que a interpreta, Alice Braga, está caracterizada de modo a evitar a sexualização de sua personagem: nunca está muito maquiada e sempre usa peças de roupa unissex, como jeans e casacos de couro. Por outro lado, é efetivamente vítima de estupro logo no começo da primeira temporada. Toda a sua trajetória de superação começa no momento do estupro, quando ela vê a si mesma no futuro como mulher rica e poderosa e, motivada por essa visão, consegue atirar no estuprador.

Além de ter uma protagonista feminina ao tratar do tráfico de drogas, o que é incomum, Queen of the South também inova por colocar outra mulher em alta posição nos negócios: a primeira chefe de Teresa é Camila Vargas, a número um no cenário de drogas de Dallas. Embora isso não seja totalmente esclarecido, sugere-se que a parte do negócio de Camila tenha sido roubada por seu marido, Epifanio Vargas, que desde então espera que Camila se recolha e aceite o papel de esposa e mãe, ao que ela se recusa e responde com medidas agressivas. Teresa e Camila serão antagonistas durante algumas temporadas e, ainda que igualmente competentes, têm estilos diferentes, pois Camila é uma mulher cruel que não hesita em matar inimigos e que está sempre com roupas curtas e justas, usando seu corpo como arma nos negócios.

\section{FEMINISMO LIBERAL E CULTURA VISUAL}

s temporadas e séries abordadas aqui procuram trazer para as narconarrativas pautas
feministas valendo-se de personagens femininas fortes, competentes e determinadas 
que desejam conquistar um lugar próprio e que têm projetos individuais de ascensão ao poder e à riqueza. Em comparação a outras séries sobre narcotráfico ou a outras temporadas da mesma série (no caso de Narcos e El chapo), isso pode significar um avanço na representação feminina, pois as mulheres saem de casa e passam a ocupar não apenas um espaço de trabalho, seja legal ou ilegal, mas também um espaço, como dissemos, muito masculino, no qual precisam lidar com preconceitos fortemente estabelecidos. Como mencionamos anteriormente, essa estratégia não está dissociada de questões comerciais com vistas à atração de um público mais amplo, de modo que já de início devemos mencionar uma aproximação entre a mudança na representação feminina e as demandas de mercado.

Nas temporadas 1 e 2 de Narcos, que representam os eventos relacionados a Pablo Escobar, as principais personagens femininas são Tata, esposa de Escobar, Hermilda, mãe de Escobar e Valeria, jornalista e amante de Escobar. A existência das três está diretamente relacionada a Pablo. Desde o início Tata e Hermilda estão cientes das atividades ilegais de Escobar e apoiam-no com sorrisos inocentes, felizes e apaixonados. 0 amor proclamado de Pablo não o impede de tomar a jornalista Valeria Velez como sua amante. Tata considera a amante uma inimiga e isenta amplamente o marido de culpa pela infidelidade. Tudo acontece como se os homens fossem incapazes de controlar seus instintos sexuais, sendo caracterizados como vítimas da sedução das mulheres.

A mãe de Pablo, Hermilda, tem uma postura inocente em relação a Pablo, além de uma boa dose de ignorância em relação a sua vilania. Para ela, Escobar ainda é como uma criança temperamental, cheia de desejos que devem ser satisfeitos. Tudo se passa como se a mãe não tivesse sido capaz de estabelecer limites à ambição e à violência do filho, aceitando passiva e alegremente suas incursões no tráfico de drogas. Portanto, sugere-se que parte da culpa pelo surgimento de um homem como Escobar se deva à sua mãe.

Nas temporadas 1 e 2 do El chapo, as mulheres estão quase completamente ausentes. Joaquín Guzmán, no início da série, tem duas esposas e depois se casa outra, uma menina muito jovem com quem tem filhas gêmeas. A poligamia de Guzmán é oficializada quando ele se torna um patrón, status pelo qual ele vinha trabalhando duro. Como patrão, Joaquín Guzmán agora tem condições simbólicas e materiais para usufruir de bens de luxo que outros homens não possuem, incluindo duas e mais tarde três esposas. Nesse caso, ser capaz de manter economicamente - e luxuosamente - várias famílias é um sinal inconfundível do status do traficante.

As esposas de Joaquín Guzmán estão sujeitas a uma divisão "sexual" do trabalho. Embora não tenham papel relevante na série, suas aparências funcionam para marcar diferentes lugares na estrutura da família. A primeira esposa, Alejandra, é mais 
velha e é a que dá bons conselhos a Joaquín. Ela o questiona sobre sua ascensão no narcotráfico, chamando a atenção para os riscos que ela implica. Por outro lado, a segunda esposa, Graciela, mais jovem, é quem Joaquín procura quando quer fazer sexo, atividade para a qual ela está sempre pronta e disposta. A imagem construída de ambas parece clara, e podemos generalizar a mensagem da série no seguinte significado: mulheres mais velhas são mais sábias, enquanto mulheres mais jovens são impetuosas e atraentes. Na segunda temporada, Joaquin terá como esposa preferida uma moça de 18 anos, Elba.

As mulheres acima citadas circulam sobretudo nos espaços abandonados por seus homens, mesmo arquitetonicamente, como as piscinas em suas casas enquanto os homens fazem negócios na sala principal. São mulheres que geralmente pertencem à família, desfrutam de uma vida de luxo e lazer e estão entre os bens de consumo dos traficantes de drogas, ou são mães simbolicamente mudas que protegem demais os filhos e permanecem afastadas ou alienadas do que acontece ao seu redor. Assim, em comparação com as imagens dessas muIheres, como mães e esposas que pouco participam de decisões de negócios, as personagens de Teresa, Berta e Isabella parecem representar uma evolução na representação feminina. Afinal, agora elas estão mostrando competência no mundo masculino, seja na política, seja no narcotráfico.

No entanto, o que essas séries entendem como conquista de espaços de poder, ou como empoderamento feminino, permanece no espectro do que foi usualmente denominado de feminismo liberal. Esse aspecto do feminismo esteve associado no passado recente a autoras como Betty Friedan, jornalista estadunidense que, no livro The feminine mystique, lançado em 1963, criticou o aprisionamento das mulheres às tarefas domésticas e à criação dos filhos. Os livros de Friedan têm como público-alvo a mulher americana heterossexual branca de classe média e analisam como o modelo de dona de casa/esposa/mãe resultou em insatisfação, depressão e alcoolismo. Sugere-se em The feminine mystique que a desigualdade de gênero chegará ao fim quando as mulheres entrarem no mercado de trabalho e se realizarem em sua profissão, ganhando um espaço para sua autoexpressão como seres humanos.

0 feminismo liberal tem sido associado mais recentemente à chamada terceira onda do feminismo e ao pós-estruturalismo. Embora o numeral dê a entender que se trata de um contínuo em relação à segunda onda, algumas autoras veem a terceira onda como um rompimento, e mesmo uma regressão, em relação à politização anterior, identificada em grande medida com o marxismo e o movimento negro. Assim como o liberalismo político, o feminismo liberal tem suas divergências internas, baseadas sobretudo no maior ou menor papel do Estado em mitigar as desigualdades entre homens e mulheres. Como o liberalismo político, 
defende a autonomia da pessoa e o direito de uma mulher viver sua vida da maneira que escolher, ainda que outras mulheres a considerem opressiva. "Escolha" talvez seja a palavra-chave do feminismo liberal: uma mulher que decida subordinar-se ao marido e viver para seus filhos pode estar praticando um ato feminista, desde que essa tenha sido uma escolha autônoma. Do mesmo modo, toleram-se a prostituição e casamentos arranjados em troca de green cards, desde que sejam decisões livres tomadas por uma mulher. Nesse sentido, um dos problemas do feminismo liberal é que o contexto social, cultural e econômico da "escolha" não é discutido.

Nas séries analisadas, o que ocorre é uma identificação do chamado empoderamento feminino ao sucesso no sistema capitalista-patriarcal — o mesmo que oprime a maioria das mulheres trabalhadoras e racializadas que sofrem com o estado mínimo e com a violência na América Latina — , representado aqui pela política e pelo narcotráfico. As personagens de Isabella, Berta e Teresa querem retirar os homens de sua posição de poder apenas para assumir o poder em seu lugar, não para mudar a estrutura que as oprime.

Apoiando-se em uma crítica marxista ao feminismo liberal, Arruzza, Bhattacharya e Fraser argumentam que as estruturas de opressão não serão alteradas trocando-se um homem por uma mulher. Elas citam algumas personagens que, segundo elas, representam 0 feminismo liberal nos Estados Unidos, como Hillary Clinton e Sheryl Sandberg:

Na primavera de 2018, a diretora de operações do Facebook, Sheryl Sandberg, disse ao mundo que "estaríamos em uma situação muito melhor se metade dos países e das empresas fosse administrada por mulheres e metade de todos os lares fosse administrada por homens". (Arruzza, Bhattacharya e Fraser, 2019: 9).

Segundo as autoras, o feminismo liberal "pede que pessoas comuns, em nome do feminismo, sejam gratas por ser uma mulher, não um homem, a desmantelar seu sindicato, a ordenar que um drone mate seu pai ou sua mãe ou a trancar seus filhos em uma jaula na fronteira" (Arruzza, Bhattacharya e Fraser, 2019: 11). Queen of the South, que à primeira vista parece ser a série mais progressista, pois duas protagonistas femininas lutam pelo poder em um ambiente muito masculino, é talvez a que mais representa esse aspecto específico do feminismo liberal, pois infere-se que o narcotráfico seria mais "humano" e menos violento se uma mulher justa como Teresa Mendoza o controlasse. Pode-se dizer que Isabella, de Narcos, México, e Berta, de El chapo, querem alcançar uma posição como a de Teresa. Seu projeto é transformarem-se nas próximas opressoras em uma estrutura violenta e corrupta.

O feminismo que circula na cultura visual hegemônica é sobretudo esse, aproximado do liberalismo e pouco crítico das estruturas de opressão, apresentado sob uma forma 
empolgante, divertida, leve e cinematograficamente bonita. Segundo Angela McRobbie, cuja obra mencionamos acima, ele parece novo e moderno, mas constitui-se em realidade em um falso feminismo, representando uma derrota para a emancipação das mulheres. Incorpora alguns temas feministas mas despolitiza-os, instrumentalizando-os para a defesa de valores patriarcais. Não questiona as desigualdades estruturais produzidas pelo modo de produção capitalista e não assusta o grande público com proposições radicais (ver também Kiraly e Tyler, 2015). Nele, sugere-se que as principais reivindicações das mulheres já foram atendidas, e por isso o feminismo já não seria mais necessário. Assim, esse falso feminismo significa uma vitória do patriarcado, uma vez que esvazia as principais reivindicações coletivas feministas, ainda que possa significar melhores oportunidades de ascensão individual para algumas mulheres.

A utilização de ideias feministas para fins antifeministas, que reforçam o capitalismo excludente, perpassa não apenas a cultura visual, mas os atos políticos e econômicos de governos e empresas com vistas à manutenção de uma estrutura internacional de opressão. A cultura visual revela-se, portanto, entranhada em uma luta política e econômica mais ampla, da qual é expressão e na qual desempenha papel ideológico fundamental. Hester Eisenstein (2015) é uma das autoras a criticar a utilização do feminismo pelo neoliberalismo e pelo imperialismo, mostrando, por exemplo, que ele foi invocado na Guerra ao Terror de George W. Bush - ocasião na qual se tratava de "libertar" mulheres muçulmanas da opressão do Islã — e no desmantelamento dos commons na África e na Ásia - que gerou empobrecimento em massa, mas que foi ressignificado pelo neoliberalismo com a ajuda das ideias feministas, por meio da concessão de microcrédito a mulheres pobres.

Capitalism as a system uses women's productive and reproductive labor, as socialist feminists have pointed out for at least two centuries. But in addition, the system is now making active use of women's ideological and political labor, taking the ideas of feminism and turning them to its own ends. (Eisenstein, 2015: xi).

\section{CONCLUSÃO}

o recusar os papéis tradicionais de esposas, mães e donas de casa, as persona-
gens de Berta, Isabella, Teresa e também Camila, sua antagonista, parecem emancipadas, modernas, "empoderadas". O feminismo para elas não é mais necessário, pois elas estão livres da maternidade, de um marido e dos afazeres domésticos que matavam de tédio a dona de casa a quem se dirigia Betty Friedan. Isabella e Berta, sobretudo, 
já alcançaram relativo sucesso em suas profissões, mas são ambiciosas e querem mais, o que é tratado como uma característica positiva das personagens. 0 sucesso parece depender apenas da capacidade dessas mulheres, de seu mérito, em destacar-se entre seus pares, seja por meios justos, como Teresa, ou desleais, como Berta. Os homens são inimigos não porque pertencem a um grupo social que obtém vantagens da exploração feminina, mas porque se encontram no caminho de sua ascensão social. Elas estão, portanto, inseridas em uma ideologia hegemônica que valoriza o sucesso individual. Embora deem ao espectador a sensação de serem produtos com mais abertura para a emancipação feminina em um gênero tão falocêntrico como as narconarrativas, as séries que abordamos representam um aspecto importante na manutenção do discurso patriarcal, na medida em que suas personagens são valorizadas porque são, elas mesmas, também muito fálicas. A valorização dessas mulheres decorre do fato de que elas emulam um comportamento masculino, ainda que com alguns "toques" femininos como o poder de sedução e a compaixão pelo outro, que funcionam para normalizar as ideias da mulher como objeto sexual e da mulher como naturalmente propensa ao cuidado com o outro.

Os produtores e roteiristas de Narcos México, El chapo (terceira temporada) e Queen of the South parecem ter identificado que as representações femininas em narconarrativas eram profundamente machistas, estabelecendo a casa e a cama de um homem como o lugar natural de uma mulher ligada ao narcotráfico. Como resposta, eles deram-nos novas personagens femininas, dialogando com outros produtos da cultura visual internacional-popular e com as atuais expectativas em relação ao papel da mulher na sociedade e procurando avançar positivamente na representação feminina. É legítimo e compreensível que muitas espectadoras também vejam nessas séries um avanço na representação feminina, uma vez que elas tematizam, por meio das personagens, uma dificuldade de inserção nas estruturas de poder político e econômico que são muito reais. Uma outra leitura, no entanto, realizada com base na metodologia dos estudos culturais e de Angela McRobbie, e que procuramos apresentar neste texto, entende que o patriarcado continua revelando-se nessas personagens, pois suas ações são valorizadas por reproduzirem a dominação masculina. As séries que analisamos compreendem o empoderamento feminino como um mundo invertido, no qual as muIheres pretendem tomar o poder dos homens sem questionar o fato de sua opressão estar profundamente enraizada na mesma estrutura social, que cria ambição, desigualdade e violência. 
Conflitos de interesse: nada a declarar.

Fonte de financiamento: Fundação de Amparo à Pesquisa do Estado de São Paulo (FAPESP), sob a modalidade Auxílio Regular, Processo n² 2018/09435-3.

\section{NOTA}

1 A associação entre melodrama e telenovelas com o público feminino é tema discutido em inúmeras obras acadêmicas, como Almeida (2002), Gledhill (1987), Hamburger (2007) e Oroz (1999).

\section{REFERÊNCIAS BIBLIOGRÁFICAS}

ALMEIDA, H. B. Melodrama comercial: reflexões sobre a feminilização da telenovela. Cadernos Pagu, Campinas, n. 19, p. 171-194, 2002. http://dx.doi.org/10.1590/S0104-83332002000200008.

ARRUZZA, C.; BHATTACHARYA, T.; FRASER, N. Feminismo para os 99\%: um manifesto. São Paulo: Boitempo Editorial, 2019.

BRAGANÇA, M. A narcocultura na mídia: notas sobre um narcoimaginário latino-americano. Significação: Revista de Cultura Audiovisual, São Paulo, v. 39, n. 37, p. 93-109, 2012. https://doi.org/10.11606/issn.23167114.sig.2012.71261.

BRAGANÇA, M. Imagens de ostentação nas narconarrativas: consumo e cultura popular. Rumores, São Paulo, v. 9, n. 17, p. 147-163, 2015.

BRUZZI, S. Undressing cinema: clothing and identity in the movies. New York: Routledge, 1997.

CABAÑAS, M. A. Imagined narcoscapes: narcoculture and the politics of representation. Latin American Perspectives, Riverside, v. 41, n. 2, p. 3-17, 2014. https://doi.org/10.1177/0094582X13518760.

CRIMP, D. Estudos culturais, cultura visual. Revista USP, São Paulo, n. 40, p. 78-85, 1999. https://doi. org/10.11606/issn.2316-9036.v0i40p78-85.

EISENSTEIN, H. Feminism seduced: how global elites use women's labor and ideas to exploit the world. New York: Routledge, 2015.

EL chapo. Direção: Ernesto Contreras; José Manuel Cravioto e outros. Produção: Isaac Lee; Camila Jimenez Villa, Daniel Posada; Christian Gabela; Andrés Calderón. Intérpretes: Marco de la 0; Humberto Busto; Alejandro Aguilar; Rodrigo Abed; Luis Fernando Peña e outros. Roteiro: Silvana Aguirre; Carlos Contreras. Música: Andrés Botero. New York: UNIVISION, c2017, 34 episódios.

ESCOSTEGUY, A. C. Uma introdução aos estudos culturais. Revista Famecos, Porto Alegre, v. 5, n. 9, p. 87-97, 1998. https://doi.org/10.15448/1980-3729.1998.9.3014.

ESTOCOLMO. Direção: Jesus Braceras e Diego Palacio. Produção: Marcelo Camaño e Lucas Molteni. Intérpretes: Juana Viale; Luciano Cáceres; Esteban Lamothe. Roteiro: Nacho Viale e Diego Palacio. Música: Dante Saulino. Buenos Aires: Netflix, c2016, 13 episódios. 
FRIEDAN, B. The feminine mystique. New York: Dell Publishing, 1963.

GLEDHILL, C. Home is where the heart is: studies in melodrama and the woman's film. United Kingdom: British Film Institute, 1987.

GRADEJA, A. D. Televisión y narcocultura. Cuando los narcos se ponen de moda. Interpretextos, Colima, año 10, n. 17, p. 87-97, 2017.

GROSSI, M. P. Masculinidades: uma revisão teórica. Antropologia em primeira mão, Florianópolis, v. 75, n. 1, p. 1-37, 2004.

HALL, S. A centralidade da cultura: notas sobre as revoluções culturais do nosso tempo. Educação \& Realidade, Porto Alegre, v. 22, n. 2, p. 16-46, 1997.

HAMBURGER, E. A expansão do "feminino" no espaço público brasileiro: novelas de televisão nas décadas de 1970 e 80. Revista Estudos Feministas, Florianópolis, v. 15, n. 1, p. 153-175, 2007. https://doi.org/10.1590/ S0104-026X2007000100010.

HENAO, V. E. Sra. Escobar - Minha vida com Pablo. São Paulo: Editora Planeta, 2019.

KIRALY, M.; TYLER, M (eds.). Freedom fallacy: the limits of liberal feminism. Brisbane: Connor Court Publishing, 2015.

LERNER, G. A criação do patriarcado: história da opressão das mulheres pelos homens. Tradução de Luiza Sellera. São Paulo: Editora Cultrix, 2019.

McROBBIE, A. The afthermath of feminism: gender, culture and social change. London: Sage, 2011.

MEDEIROS, M.; CASTRO, T. 0 que é a cultura visual? Revista de Comunicação e Linguagens, Lisboa, n. 47, p. 1-7, 2017.

MITCHELL, W. J. T. Mostrar o ver: uma crítica à cultura visual. Interin, Curitiba, v. 1, n. 1, p. 1-20, 2006.

NARCOS. Direção: André Baiz; Josej Kubota Wladyka; Fernando Coimbra; Gerardo Naranjo e outros. Produção: Paul Eckstein; Mariano Carranco; Tim King; Lorenzo O'Brien e outros. Intérpretes: Wagner Moura; Boyd Holbrook; Pedro Pascal; Joann Christie; Maurice Compte; André Mattos; Roberto Urbina e outros. Roteiro: Carlo Bernard; Chris Brancato; Doug Miro; Andrew Black; Clayton Trussel; Dana Ledoux Miller e outros. Música: Rodrigo Amarante. West Hollywood: Gaumont International Television, c2016, 30 episódios.

NARCOS: México. Direção: Andrés Baiz; Amat Escalante; Alonso Ruizpalacios; Jofef Kubota Wladyka; Marcela Said. Produção: Carlo Bernard: Doug Miro: Eric Newman; José Padilha. Intérpretes: Michael Peña; Diego Luna; Tenoch Huerta Mejía; Alyssa Diaz; Joaquín Cosío e outros. Roteiro: Carlo Bernard; Chirs Brancato; Doug Miro; Eva Aridjis e outros. Música: Gustavo Santaolalla; Kevin Kiher. Los Gatos: Netflix. c2018, 21 episódios.

OROZ, S. Melodrama: o cinema de lágrimas da América Latina. Rio de Janeiro: Funarte, 1999. v. 1.

ORTIZ, R. Uma cultura internacional-popular. In: ORTIZ, R. Mundialização e cultura. São Paulo: Editora Brasiliense, 1994. p. 105-145.

ORTIZ, R. Estudos culturais. Tempo Social, São Paulo, v. 16, n. 1, p. 119-127, 2004. https://doi.org/10.1590/ S0103-20702004000100007.

PÉREZ-REVERTE, A. La reina del sur. Madrid: Alfaguara, 2002. 
POBUTSKY, A. B. Peddling Pablo: Escobar's Cultural Renaissance. Hispania, Baltimore, v. 96, n. 4, p. 684-699, 2013. https://doi.org/10.1353/hpn.2013.0104.

QUEEN of the South. Direção: Eduardo Sánchez e outros. Produção: Robert J. Wilson e Lorenzo O'Brien. Intérpretes: Alice Braga; Hemky Madera; Peter Gadiot; Veronica Falcón; Joaquim de Almeida e outros. Roteiro: Scott Rosenbaum, M. A. Fortin, Joshua John Miller, Arturo Pérez-Reverte. Música: Giorgio Moroder e Raney Shockne. New York: USA Network, c2016, 62 episódios.

RINCÓN, O. Todos temos um pouco do tráfico dentro de nós: um ensaio sobre o narcotráfico/cultura/novela como modo de entrada para a modernidade. Matrizes, São Paulo, v. 7, n. 2, p. 163-219, 2013.

WILLIAMS, R. Marxismo e literatura. Rio de Janeiro: Zahar, 1979. 